\title{
Glycemic Control and its Determinants among Ambulatory Patients with Type 2 Diabetes
}

\section{Tessema Tsehay Biru*}

Department of Pharmacy, College of Health Sciences, Mizan Tepi University, Mizan Aman, Ethiopia

*Corresponding authors: Tessema Tsehay Biru, Department of Pharmacy, Colege of Health Sciences, Mizan Tepi University, Mizan Aman, Ethiopia, Tel: +251913695843; E-mail: tessema.tsehay@gmail.com

Received date: August 01, 2017; Accepted date: August 17, 2017; Published date: August 22, 2017

Copyright: (C) 2017 Biru TT. This is an open-access article distributed under the terms of the Creative Commons Attribution License, which permits unrestricted use, distribution, and reproduction in any medium, provided the original author and source are credited.

\begin{abstract}
Background: Diabetes Mellitus has become one of the most important public health challenges of the 21st century. The rate of increase in the incidence will be dramatically higher in developing countries and is paralleled by a skyrocketing increase in its chronic complications responsible for the huge premature morbidity and mortality associated with the disease. The development of long-term complications is influenced by hyperglycemia and poor control of diabetes could accelerate their progression.
\end{abstract}

Methods: A cross sectional study was conducted to determine the adequacy of glycemic control and identify factors associated with poor glycemic control. Three hundred twenty two ambulatory patients with Type 2 diabetes mellitus were involved in the study. It was a two phase study where data collection was carried out between May 01 and June 30, 2014. The most recent fasting blood sugar level was used for assessing glycemic control.

Results: Only $12.7 \%$ of patients attained adequate glycemic control. Male sex, younger age, low educational status, regular alcohol intake, exercise and dietary non-adherence were observed to be significantly associated with poor glycemic control. Study findings showed that glycemic control was poor, which requires health care professionals to seriously address the issue in order to achieve a better diabetes care.

Keywords: Type 2 Diabetes, Glycemic control, Fasting blood sugar (FBS), Morisky

\section{Introduction}

Diabetes Mellitus (DM) is an endocrine disorder of various etiologies manifested by long term hyperglycemia, which causes significant physical and psychological morbidity, disability and premature mortality among those affected patients and imposes a heavy financial burden on health services [1,2]. Generally, $40 \%$ of patients with diabetes will develop microvascular or macrovascular complications in the course of their disease [3]. The vast majority of cases of diabetes fall into two broad categories: type 1 and 2 diabetes $[2,4]$. The prevalence of Type-2 diabetes is alarmingly growing around the globe with $80 \%$ of the affected individuals residing in low and middle income countries, including Ethiopia. More than $4 \%$ of Ethiopians are estimated to live with diabetes mellitus in the year 2013. [5].

DM has become one of the most important public health challenges of the 21st century. The rate of increase in the incidence will be dramatically higher in developing countries and is paralleled by a skyrocketing increase in its chronic complications responsible for the huge premature morbidity and mortality associated with the disease [6]. The development of long-term complications is influenced by hyperglycemia and poor control of diabetes could accelerate their progression [7]. One of the primary goals of diabetes management therefore is to lower blood glucose levels because it is well established that improved glycemic control delays the onset and retards the progression of these complications of microvascular and macrovascular type [8]. As such, regular testing of blood glucose is a cornerstone and achievement of adequate glycemic control is a goal for proper diabetes car [4]. It is recognized that there are limited research works doneinn the area in Ethiopia, therefore the present study was conducted to assess the level of glycemic control and factors associated with poor glycemic control among ambulatory type 2 diabetic patients. The findings are believed to be utilized in the betterment of diabetes care service in Ethiopia and other areas in general.

\section{Materials and Methods}

A cross sectional study was conducted in two-phases: patient interview and chart review. Patient interviews and medical record reviews were conducted from 1st of May to 30th of June, 2014. The sample size calculated using single population proportion formula was 385 . As the actual number of source population in the study period was 120 , the corrected sample size, using a correction formula was 292; a $10 \%$ contingency yielded a final sample size of 322 . Systematic random sampling method was used to recruit samples for the study. All patients with type 2 diabetes and on treatment with anti-diabetic drugs at least for 3 months, who were $\geq 18$ years of age and who understood the local language were included in the study. A questionnaire was utilized to gather information about patients' sociodemographic characteristics, duration of diabetes, knowledge about diabetic complications, medication adherence and self-management practices of diabetic care. Information on fasting blood sugar, comorbidities, diabetic complications, and prescribed medications was obtained from reviewing individual patient medical records. 
Citation: Tessema Tsehay Biru (2017) Glycemic Control and its Determinants among Ambulatory Patients with Type 2 Diabetes. J Diabetes

Page 2 of 7

The data collection instruments were assessed by a physician and expert in the field of endocrinology for clarity and comprehensiveness of contents. Pre-testing of the instruments was also done among $5 \%$ of randomly selected, type 2 diabetes patients, who were not included in the study, ahead of the start of the main data collection. Good/ Adequate glycemic control was regarded as Fasting Blood Sugar (FBS) $\leq 110 \mathrm{mg} / \mathrm{dL}[8,9]$. The collected data was entered into Epi Info v-3.5.3 and analyzed using SPSS v-21. Descriptive statistics including: frequency, mean and standard deviation were used to summarize patients' baseline socio-demographic data and evaluate the distribution of responses. Crude and Adjusted Odds Ratio (COR/ AOR) were calculated and 95\% confidence level was used to determine factors associated with poor glycemic control. A p-value of 0.05 or less was considered statistically significant. Ethical clearance and approval of the study protocols was granted. Prior to data collection, individual informed verbal consent was obtained from the study patients.

\section{Results}

\section{Socio-demographic characteristics}

Females comprised 59.3\% of the sex category. Majority of the patients were in the age group of 51-60 years, which accounted for $30.7 \%$. The mean age of the studied population was $52.68(\mathrm{SD}=11.17)$ years (range 18 to 82 years). Being a Housewife $(98,30.4 \%)$ accounted for the highest percentage of occupation. Patients with higher education $(94,29.2 \%)$ constituted the highest percentage of educational status category (Table 1 ).

\begin{tabular}{|c|c|c|c|}
\hline \multicolumn{2}{|l|}{ Variables } & \multirow{2}{*}{$\begin{array}{l}\text { Frequency } \\
131\end{array}$} & \multirow{2}{*}{$\begin{array}{l}\text { Percent (\%) } \\
40.7\end{array}$} \\
\hline & Male & & \\
\hline & Female & 191 & 59.3 \\
\hline \multirow{5}{*}{ Age (Years) } & $\leq 40$ & 51 & 15.8 \\
\hline & $41-50$ & 93 & 28.9 \\
\hline & $51-60$ & 99 & 30.7 \\
\hline & $61-70$ & 58 & 18 \\
\hline & $>70$ & 21 & 6.5 \\
\hline \multirow{4}{*}{ Marital Status } & Single & 42 & 13 \\
\hline & Married & 194 & 60.2 \\
\hline & Divorced & 39 & 12.1 \\
\hline & Widowed & 47 & 14.6 \\
\hline \multirow{8}{*}{ Occupation } & House Wife & 98 & 30.4 \\
\hline & Government Employee & 62 & 19.3 \\
\hline & Retired & 54 & 16.8 \\
\hline & Merchant/Trade & 48 & 14.9 \\
\hline & Unemployed & 19 & 5.9 \\
\hline & Farmer & 10 & 3.1 \\
\hline & Daily Laborer & 7 & 2.2 \\
\hline & Others & 24 & 7.5 \\
\hline \multirow{4}{*}{ Educational Status } & Cannot Read and Write & 70 & 21.7 \\
\hline & Primary & 91 & 28.3 \\
\hline & Secondary & 67 & 20.8 \\
\hline & Higher Education & 94 & 29.2 \\
\hline
\end{tabular}

Table 1: Socio-demographic characteristic of patients with type 2 diabetes. 
Citation: Tessema Tsehay Biru (2017) Glycemic Control and its Determinants among Ambulatory Patients with Type 2 Diabetes. J Diabetes

Page 3 of 7

\section{Self-management practices of diabetes care}

The self-management practices of diabetes care for the studied patients included: diet restriction $(207,64.3 \%)$, exercise $(69,21.4 \%)$, self-monitoring of blood glucose (SMBG) $(11,7.4 \%)$, never drink alcohol regularly $(235,71.0 \%)$ and never smoke $(285,88.5 \%)$. None of the patients had dietary plans prepared with their physicians, but majority of them were simply told to cut off sweet carbohydrate and fatty meals (Table 2).

\begin{tabular}{|c|c|c|c|c|}
\hline \multicolumn{3}{|l|}{ Variables } & \multirow{2}{*}{$\begin{array}{l}\text { Frequency } \\
276\end{array}$} & \multirow{2}{*}{$\begin{array}{l}\text { Percent } \\
85.7\end{array}$} \\
\hline \multirow[b]{4}{*}{ DIET } & \multirow[b]{2}{*}{ Dietary Approach } & Cut off Sweet Carbohydrate Meals & & \\
\hline & & Cut off Fatty Meals & 216 & 67.1 \\
\hline & \multirow[b]{2}{*}{ Overall Dietary Adherence } & No & 115 & 35.7 \\
\hline & & Yes & 207 & 64.3 \\
\hline \multirow[b]{10}{*}{ EXERCISE } & \multirow{2}{*}{$\begin{array}{l}\text { Presence of agreed Exercise plan with } \\
\text { physicians }\end{array}$} & No & 253 & 78.6 \\
\hline & & Yes & 69 & 21.4 \\
\hline & \multirow[b]{2}{*}{ Exercising According to Plan $(n=69)$} & No & 42 & 60.9 \\
\hline & & Yes & 27 & 39.1 \\
\hline & \multirow{2}{*}{$\begin{array}{l}\text { Days per Week Doing Moderate Intense } \\
\text { Exercise }\end{array}$} & $<3$ Days & 101 & 31.4 \\
\hline & & $\geq 3$ Days & 220 & 68.6 \\
\hline & \multirow{2}{*}{$\begin{array}{l}\text { Duration of Moderate Intense Exercise per } \\
\text { Week in Minutes }\end{array}$} & $<150$ Minutes & 260 & 80.7 \\
\hline & & $\geq 150$ Minutes & 62 & 19.3 \\
\hline & \multirow[b]{2}{*}{ Overall Exercise Adherence } & No & 260 & 80.7 \\
\hline & & Yes & 62 & 19.3 \\
\hline \multirow[b]{6}{*}{ ALCOHOL } & \multirow[b]{2}{*}{ Ever Drink Regularly } & No & 235 & 71 \\
\hline & & Yes & 87 & 27 \\
\hline & \multirow[b]{2}{*}{ Drinking Regularly Now $(n=87)$} & No & 85 & 97.7 \\
\hline & & Yes & 2 & 2.3 \\
\hline & \multirow[b]{2}{*}{ How much Drink Servings Per Day(n=2) } & $\leq 2$ for Males and $\leq 1$ for Females & $1^{*}$ & 50 \\
\hline & & $>2$ for Males and $>1$ for Females & $1^{*}$ & 50 \\
\hline \multirow[b]{6}{*}{ CIGARETTE } & \multirow[b]{2}{*}{ Ever Smoked } & No & 285 & 88.5 \\
\hline & & Yes & 37 & 11.5 \\
\hline & \multirow[b]{2}{*}{ Smoking Now $(n=37)$} & No & 28 & 75.7 \\
\hline & & Yes & 9 & 24.3 \\
\hline & & $<$ Half a Pack & 7 & 77.8 \\
\hline & Amount of Cigarettes Per Day in Packs $(n=9)$ & Half a Pack & 2 & 22.2 \\
\hline \multirow{4}{*}{$\begin{array}{l}\text { SELF-MONITORING OF BLOOD } \\
\text { GLUCOSE (SMBG) }\end{array}$} & \multirow[b]{2}{*}{ Presence of Glucometer } & No & 174 & 54 \\
\hline & & Yes & 148 & 46 \\
\hline & \multirow{2}{*}{$\begin{array}{l}\text { Number of Blood Glucose Measurements } \\
\text { Per Week }(n=148)\end{array}$} & $<1$ Time Per day & 137 & 92.6 \\
\hline & & $\geq 1$ Time Per day & 11 & 7.4 \\
\hline
\end{tabular}

Table 2: Self-management practices of diabetic care among type 2 diabetic patients. 
Citation: Tessema Tsehay Biru (2017) Glycemic Control and its Determinants among Ambulatory Patients with Type 2 Diabetes. J Diabetes

Page 4 of 7

\section{Antidiabetic medication adherence}

Assessment of patients' responses to a 4-item Morisky adherence predictor scale showed that $215(66.8 \%)$ patients were adherent to the prescribed regimen of their antidiabetic medications. the trend of glycemic control among the study population. Accordingly, only $41(12.7 \%)$ patients attained adequate glycemic control. The mean glycemic level was $192.7(\mathrm{SD}=76.5) \mathrm{mg} / \mathrm{dl}$, with a range value of 52.0 to $444.0 \mathrm{mg} / \mathrm{dl}$ (Table 3 ).

\section{Glycemic control using fasting blood sugar}

The most recent FBS value was regarded as the measure of glycemic control in this study, while the other values collected were used to see

\begin{tabular}{|c|c|c|c|c|}
\hline \multirow[b]{2}{*}{ FBS Values } & \multicolumn{4}{|l|}{ Frequency (\%) } \\
\hline & $\leq 110 \mathrm{mg} / \mathrm{dl}$ (Adequate) & $>110 \mathrm{mg} / \mathrm{dl}$ (Inadequate) & Mean (SD) mg/dl & $\operatorname{Min}(\operatorname{Max}) \mathrm{mg} / \mathrm{dl}$ \\
\hline Most Recent Value ( $n=322)$ & $41(12.7)$ & $281(87.3)$ & $192.7(76.5)$ & $52.0(444.0)$ \\
\hline Last appointment $(\mathrm{n}=312)$ & $55(17.5)$ & $259(82.5)$ & $180.4(74.8)$ & $48.0(427.0)$ \\
\hline Second last appointment $(n=310)$ & $55(17.6)$ & $257(82.4)$ & $193.2(88.3)$ & $47.0(490.0)$ \\
\hline $\begin{array}{l}\text { First appointment } \\
(\mathrm{n}=318)\end{array}$ & $7(2.2)$ & $311(97.8)$ & $268.8(103.6)$ & $81.0(650.0)$ \\
\hline Most Recent SMBG ( $n=109)$ & $19(17.4)$ & $91(82.6)$ & $178.5(69.5)$ & $45.0(400.0)$ \\
\hline
\end{tabular}

Table 3: Fasting blood sugar measurements of type 2 diabetic patients.

\section{Treatment adherence and glycemic control}

Among 215 (66.8\%) patients who reported adherent to their antidiabetic medications, 29 (13.5\%) of them attained adequate glycemic control. However, among the 29 (9\%) patients who adhered to all treatment recommendations (antidiabetic medications, dietary \& exercise recommendations), 7 (24.1\%) of them attained adequate glycemic control (Table 4).

\begin{tabular}{|l|l|l|l|}
\hline \multirow{2}{*}{} & \multicolumn{2}{|l|}{ Adequacy of glycemic control } & Total \\
\cline { 2 - 4 } & Poor/Inadequate & Good/Adequate & $215(100 \%)$ \\
\hline Antidiabetic Medication adherent & $186(86.5 \%)$ & $29(13.5 \%)$ & $29(100 \%)$ \\
\hline Overall treatment adherent & $22(75.9 \%)$ & $7(24.1 \%)$ & $2 \%$ \\
\hline
\end{tabular}

Table 4: Treatment adherence and glycemic control among type 2 diabetic patients.

\section{Factors associated with glycemic control}

The present study revealed that sex, age, educational status, dietary adherence, exercise adherence and ever drinking alcohol were found to be significantly associated with glycemic control during a multivariate logistic regression analysis (Table 5).

\section{Discussion}

The glycemic control in the present study was only adequate for $12.7 \%$ of the study population, which made the glycemic control to be very poor and inadequate. This result was lower than the results from various studies, which reported a rate ranging from $17 \%$ to $62 \%$ [10-15]. The management of DM ensures normal FBS levels necessary for short-term and long-term control and reduction of acute and chronic complications. Glycemic control is a strong predictor of diabetes complications, particularly microvascular complications.
Failure in achievement of clinical blood glucose targets is therefore of phenomenal importance and can lead to increased hospital visits, preventable emergency admissions and deaths. In the present study, female patients were found to have adequate glycemic control compared with male counterparts.

This finding was in agreement with Nigerian and Indian studies which reported male sex as a risk factor for poor glycemic control $[10,12]$. On the other hand, educational status was shown to have a positive association with glycemic control. As patients' educational status gets increased, the likelihood of attaining adequate control was also increased. Some studies also revealed similar findings which stated that low educational status is associated with inadequate glycemic control [16-19]. Education is undoubtedly essential for the achievement of the high standards of self-management on which good diabetic control depends. 
Citation: Tessema Tsehay Biru (2017) Glycemic Control and its Determinants among Ambulatory Patients with Type 2 Diabetes. J Diabetes Metab 8: 757. doi:10.4172/2155-6156.1000757

Page 5 of 7

\begin{tabular}{|c|c|c|c|c|}
\hline \multirow[t]{2}{*}{ Variables } & \multicolumn{2}{|c|}{ Glycemic Control } & \multirow{2}{*}{ COR , $95 \% \mathrm{Cl}$} & \multirow{2}{*}{ AOR, $95 \% \mathrm{Cl}$} \\
\hline & No (\%) & Yes (\%) & & \\
\hline \multicolumn{5}{|l|}{ Sex } \\
\hline Male & $121(92.4)$ & $10(7.6)$ & 1 & 1 \\
\hline Female & $160(83.8)$ & $31(16.2)$ & $2.34(1.11,4.97)^{*}$ & $3.47(1.22,9.91)^{*}$ \\
\hline \multicolumn{5}{|l|}{ Age Category } \\
\hline$\leq 40$ & $46(90.2)$ & $5(9.8)$ & 1 & 1 \\
\hline $41-50$ & $87(93.5)$ & $6(6.5)$ & $1.51(0.38,5.95)$ & $2.82(0.62,12.74)$ \\
\hline $51-60$ & $86(86.9)$ & $13(13.1)$ & $2.42(0.66,8.91)$ & $3.22(0.76,13.70)$ \\
\hline $61-70$ & $46(79.3)$ & $12(20.7)$ & $4.17(1.11,15.75)^{\star}$ & $8.32(1.76,39.35)^{\star}$ \\
\hline$\geq 71$ & $16(76.2)$ & $5(23.8)$ & $5.00(1.07,23.30)^{\star}$ & $31.30(4.07,240.90)^{\star}$ \\
\hline \multicolumn{5}{|l|}{ Educational Status } \\
\hline Cannot Read and Write & $65(92.9)$ & $5(7.1)$ & 1 & 1 \\
\hline Primary & $77(84.6)$ & $14(15.4)$ & $4.76(1.33,17.07)^{\star}$ & $13.66(2.94,63.55)^{\star}$ \\
\hline Secondary & $57(85.1)$ & $10(14.9)$ & $3.92(1.03,14.93)^{*}$ & $20.09(3.80,106.14)^{*}$ \\
\hline Higher Education & $82(87.2)$ & $12(12.8)$ & $3.27(0.89,12.06)$ & $20.72(3.78,113.51)^{\star}$ \\
\hline \multicolumn{5}{|c|}{ Ever Drink Alcohol Regularly } \\
\hline No & 201(85.5) & $34(14.5)$ & 1 & 1 \\
\hline Yes & $80(92.0)$ & $7(8.0)$ & $0.19(0.06,0.62)^{*}$ & $0.15(0.03,0.65)^{\star}$ \\
\hline \multicolumn{5}{|l|}{ Total Number of Drugs } \\
\hline 1 & $23(79.3)$ & $6(20.7)$ & 1 & 1 \\
\hline 2 & $74(92.5)$ & $6(7.5)$ & $1.10(0.28,4.37)$ & $1.30(0.26,6.54)$ \\
\hline 3 & $48(90.6)$ & $5(9.4)$ & $0.90(0.20,4.008)$ & $1.26(0.22,7.33)$ \\
\hline 4 & $64(87.7)$ & $9(12.3)$ & $1.22(0.31,4.86)$ & $1.56(0.29,8.32)$ \\
\hline 5 & $35(77.8)$ & 10(22.2) & $2.48(0.62,9.91)$ & $3.16(0.59,16.96)$ \\
\hline$>5$ & $37(88.1)$ & $5(11.9)$ & $1.17(0.26,5.34)$ & $1.18(0.19,7.14)$ \\
\hline \multicolumn{5}{|c|}{ Antidiabetic Medication Adherence } \\
\hline No & $95(88.8)$ & $12(11.2)$ & 1 & \\
\hline Yes & $186(86.5)$ & $29(13.5)$ & $1.23(0.60,2.53)$ & \\
\hline \multicolumn{5}{|l|}{ Dietary Adherence } \\
\hline No & 106(92.2) & $9(7.8)$ & 1 & 1 \\
\hline Yes & $175(84.5)$ & $32(15.5)$ & $2.15(0.99,4.69)$ & $3.27(1.23,8.67)^{*}$ \\
\hline \multicolumn{5}{|l|}{ Exercise Adherence } \\
\hline No & 233(89.6) & $27(10.4)$ & 1 & 1 \\
\hline Yes & $48(77.4)$ & $14(22.6)$ & $2.52(1.23,5.15)^{*}$ & $3.37(1.39,8.20)^{*}$ \\
\hline
\end{tabular}

Table 5: Multivariate logistic regression analysis result of factors associated with glycemic control among type 2 diabetic patients. 
Regarding age, older patients were found to have higher odds of attaining adequate control than younger patients. The finding that younger age was associated with worse glycemic control is congruent with similar [18,20-24]. It is not fully understood why younger patients have worse glycemic control than older patients. These patients have a higher lifetime risk of developing micro- and macro-vascular complications. They might be more likely to disregard diabetes as being important and could be less adherent to medications, lifestyle and diet restrictions. On the contrary, older patients might be more motivated to take care of their diabetes and be more compliant with their medication, regular physical activity and eat healthy low-fat diet.

In the present study, patients who were adherent for both exercise and dietary recommendations were more likely to adequately control their blood glucose levels, compared to their respective counterparts. Similar studies also reported consistent findings with respect to these variables [17,21,25-29]. In the present study, however, in spite of the significant association, only $64.3 \%$ and $21.4 \%$ of the patients were found to be adherent to diet and exercise recommendations, respectively. Attaining adequate glycemic control is not solely dependent on adherence to medications; rather it needs a multimodal approach including adherence to dietary and exercise recommendations. Despite the benefits in type 2 diabetes, research has noted that healthcare professionals inadequately address this issue, resulting in physical activity being an underutilized therapy. Thus, it is a matter of necessity to educate patients with type 2 diabetes at their every visit to their physician about the importance of these lifestyle modifications.

In this study, patients who ever drunk alcohol regularly were found to have lesser odds of controlling their glycemic level compared to those who never drunk regularly. Various studies showed that alcohol consumption is inversely associated with glycemic control among diabetes patients [30,31]. The greatest impact of alcohol is seen in those who drink heavily on a frequent basis. Along with the impact on blood sugar, studies have also shown that alcohol can impact the effectiveness of the hypoglycemic medications, so extreme caution needs to be taken when consuming alcohol by anyone with diabetes. Given the tremendous disease burden and financial costs associated with diabetes complications, understanding modifiable predictors of diabetes disease course has great public health significance. Alcohol consumption is a very common, potentially modifiable behavior that may impact diabetes disease course. Being a retrospective study and use of FBS as a measure of glycemic control were the main limitations of the study; hence caution has to be exercised in interpreting the findings of the study taking into consideration of these limitations.

\section{Conclusions}

Despite the use of multiple antidiabetic medications (both oral and insulin), only $12.7 \%$ of patients attained adequate glycemic control, which indicated that there was poor glycemic control among the study population. Younger age, male sex, low educational status, drinking alcohol regularly and each of exercise and dietary non-adherence were factors that had a significant association with poor glycemic control. A relatively higher antidiabetic medication adherence rate did not appear to have an appreciable effect on patients' fasting blood glucose values, as a sizeable number of patients had an FBS above the recommended glycemic goals indicative of adequate control. In view of the adverse effects of hyperglycemia leading to severe morbidity and increased mortality among the diabetic patients, a tight control of blood glucose level is mandatory. As a sizable number of patients had poor control relative to the number of patients who adhered to antidiabetic medications, the efforts of health professionals engaged in diabetic care also should gear towards ensuring patient's adherence to other aspects of diabetes management plan, including diet and exercise adherence, so as to optimize outcome. Larger studies are required to look the association between antidiabetic medication adherence and glycemic control in the study area.

\section{Acknowledgement}

First and foremost I extend our gratitude for God who helped me a lot to make the study very successful. I would also like to thank Addis Ababa University for providing materials and stationeries required for the study.

\section{References}

1. EUDIP Group (2002) Establishment of indicators monitoring diabetes mellitus and its morbidity.

2. WHO (1999) Definition, Diagnosis and Classification of Diabetes Mellitus and its Complications Part 1: Diagnosis and Classification of Diabetes Mellitus.

3. MacKinnon NJ, Hartnell NR, Black EK, Dunbar P, Johnson J, et al. (2008) Development of clinical indicators for Type 2 Diabetes. CPJ/RPC 141: 119-128.

4. American Diabetes Association (2013) Standards of Medical Care in Diabetes. Diabetes Care. 37: 14-80.

5. International Diabetes Federation. IDF Diabetes Atlas 6th edition.

6. Nicolucci A, Greenfield S, Mattke S (2006) Selecting indicators for the quality of diabetes care at the health systems level in OECD countries. Int J Qual Heal Care 18 Suppl 1: 26-30.

7. World Health Organization (1994) Management of Diabetes Mellitus: Standards of care and clinical practice guidelines.

8. UK Prospective Diabetes Study Group (1998) Intensive blood glucose control with sulphonylureas or insulin compared with conventional treatment and risk of complications in patients with type 2 diabetes (UKPDS 33). Lancet 352: 837-853.

9. Garber AJ, Abrahamson MJ, Barzilay JI, Blonde L, Bloomgarden ZT, et al. (2013) American Association of Clinical Endocrinologist's Comprehensive diabetes management algorithm consensus statementexecutive summary. Endocr Pract 19: 536-557.

10. Adisa R, Fakeye TO, Fasanmade A (2011) Medication adherence among ambulatory patients with type 2 diabetes in a tertiary healthcare setting in southwestern Nigeria. Pharm Pract (Granada) 9: 72-81.

11. Chua SS, Chan SP (2011) Medication adherence and achievement of glycaemic targets in ambulatory type 2 diabetic patients. J App Pharm Sci 1: 55-59.

12. Gopinath B, Prasad SM, Jayarama N, Prabhakara K (2013) Study of factors associated with poor glycemic control in Type-2 Diabetic patients. Glob J Med Public Heal 2.

13. Pascal IGU, Ofoedu JN, Uchenna NP, Nkwa A, Uchamma GUE (2012) Blood glucose control and medication adherence among adult type 2 diabetic Nigerians attending a primary care clinic in under-resourced environment of eastern Nigeria. N Am J Med Sci 4: 310-315.

14. Rwegerera GM (2014) Adherence to antidiabetic drugs among patients with Type 2 diabetes mellitus at Muhimbili National Hospital, Dares Salaam, Tanzania- A cross-sectional study. Pan Afr Med J 17: 252.

15. Wabe TN, Angamo MT, Hussein S (2011) Medication adherence in diabetes mellitus and self-management practices among type-2 diabetics in Ethiopia. N Am J Med Sci 3: 418-423.

16. Goudswaard AN, Stolk RP, Zuithoff P, Rutten GE (2004) Patient characteristics do not predict poor glycaemic control in type 2 diabetes patients treated in primary care. Eur J Epidemiol 19: 541-545. 
Citation: Tessema Tsehay Biru (2017) Glycemic Control and its Determinants among Ambulatory Patients with Type 2 Diabetes. J Diabetes Metab 8: 757. doi:10.4172/2155-6156.1000757

Page 7 of 7

17. Khattab M, Khader YS, Al-Khawaldeh A, Ajlouni K (2010) Factors associated with poor glycemic control among patients with type 2 diabetes. J Diabetes Complicat 24: 84-89.

18. Mansour AA, Aal-Maliky A, Kasem B (2013) Determinants of loss of glycemic control in patients with type 1 diabetes mellitus. Prospective cohort study from Iraq. J Diabetes Res Clin Metab 2: 1-4.

19. Sastre J, Pines P, Moreno J, Aguirre M, Blanco B, et al. (2012) Association between educational level with glycemic and risk factor control in type 1 diabetes: results from DIACAM 1 study. Endocr Abstr 29: 580.

20. Centers for Disease Control and Prevention (CDC) (2012) Use of Selected Clinical Preventive Services Among Adults-United States , 2007-2010. 2012 p. Morb Mortal Wkly Rep 61 Suppl: 32-37.

21. Chiu CJ, Wray LA (2010) Factors predicting glycemic control in middleaged and older adults with type 2 diabetes. Prev Chronic Dis 7: A08.

22. Hessler DM, Fisher L, Mullan JT, Glasgow RE, Masharani U (2012) Patient age: a neglected factor when considering disease management in adults with type 2 diabetes. Patient Educ Couns 85: 154-159.

23. Juarez DT, Sentell T, Tokumaru S, Goo R, Davis JW, et al. (2012) Factors Associated With Poor Glycemic Control or Wide Glycemic Variability Among Diabetes Patients in Hawaii, 2006-2009. Prev Chronic Dis 9: 120065.

24. Naranjo DM, Jacobs EA, Fisher L, Hessler D, Fernandez A (2013) Age and glycemic control among low-income Latinos. J Immigr Minor Heal 15: 898-902.
25. Castañeda-González LM, Bacardí GM, Jiménez CA (2011) Effects of low carbohydrate diets on weight and glycemic control among type 2 diabetes individuals: a systemic review of RCT greater than 12 weeks. Nutr Hosp 26: $1270-1276$

26. Davison KA, Negrato CA, Cobas R, Matheus A, Tannus L, et al. (2014) Relationship between adherence to diet, glycemic control and cardiovascular risk factors in patients with T1DM: a nationwide survey in Brazil. Nutr J 13: 19.

27. Haimoto H, Sasakabe T, Wakai K, Umegaki H (2009) Effects of a lowcarbohydrate diet on glycemic control in outpatients with severe type 2 diabetes. Nutr Metab 6: 21

28. Marwick TH, Hordern MD, Miller T, Chyun DA, Bertoni AG, et al (2009) Exercise training for T2DM: impact on cardiovascular risk: a scientific statement from the American Heart Association. Circulation 119: 3244-3262.

29. Van Dijk JW, Manders RJ, Canfora EE, Mechelen WV, Hartgens F, et al. Exercise and 24-h glycemic control: equal effects for all type 2 diabetes patients? Med Sci Sport Exer 45: 628-635.

30. Ahmed AT, Karter AJ, Warton EM, Doan JU, Weisner CM (2008) The relationship between alcohol consumption and glycemic control among patients with diabetes: the Kaiser Permanente Northern California Diabetes Registry. J Gen Intern Med 23: 275-282.

31. Emanuele NV, Swade TF, Emanuele MA (1998) Consequences of Alcohol Use in Diabetics. Alcohol Heal Res World 22: 211-219. 